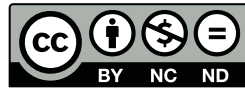

Estudos Teológicos foi licenciado com uma Licença Creative Commons Atribuição - NãoComercial - SemDerivados 3.0 Não Adaptada

http://dx.doi.org/10.22351/et.v58i1.3050

\title{
UM DIÁlOGO POSSÍVEL ENTRE TEOLOGIA E SOCIEDADE: ASSISTÊNCIA ESPIRITUAL NOS CUIDADOS EM FINAL DE VIDA ${ }^{1}$
}

\author{
One possible dialogue between Theology and society: \\ Spiritual assistance in end-of-life care
}

\section{Marcia Regina Chizini Chemin ${ }^{2}$ Waldir Souza ${ }^{3}$}

\begin{abstract}
Resumo: Desafios se apresentam à Teologia na esteira do desenvolvimento tecnológico, em especial, devido às consequências que levam o ser humano mesmo gravemente doente a viver por mais tempo. A longevidade em si, também aumentada pelos efeitos do desenvolvimento das ciências médicas, traz à cena cotidiana cada vez mais idosos com doenças crônico-degenerativas. Todos, a seu modo, apresentarão quadro de doença crônica, que se estenderá por anos, e, muito provavelmente, ao entrarem em fase final de doença, serão pacientes elegíveis aos Cuidados Paliativos. A morte não se dará em um instante inesperado, ao contrário, será esperada e prevista. A vida que se alonga apresenta uma nova realidade: experiências humanas que não existiam no passado. Assim, uma nova reflexão teológica surge provocada pela realidade experimentada. A questão está posta à Teologia, pois implica o ser humano, sua espiritualidade e sua busca por sentido de viver. O cuidado humanizado e integral que respeite o protagonismo do paciente é preocupação da Bioética no auxílio à prática do cuidado médico. A partir de breve revisão bibliográfica, observou-se que há confusão entre conceitos determinantes como religião e espiritualidade, e que há necessidade de formar assistentes espirituais para atuarem no cuidado aos enfermos como facilitadores de tratamento.
\end{abstract}

Palavras-chave: Assistência espiritual. Cuidados Paliativos. Bioética. Teologia.

Abstract: Challenges present themselves to Theology in the wake of technological development, especially due to the consequences that lead the seriously ill human being to live longer. Longevity itself, also augmented by the effects of the development of

1 O artigo foi recebido em 01 de julho de 2017 e aprovado em 19 de novembro de 2017 com base nas avaliações dos pareceristas ad hoc.

2 Mestre em Bioética. Doutorado em Teologia (em andamento) pelo Programa de Pós-Graduação em Teologia da Pontifícia Universidade Católica do Paraná (PUCPR). Membro do Grupo de Pesquisa Bioética e Humanização do Cuidado em Saúde (BIOHCS) CNPq/PUCPR. Contato: maychizini@yahoo.com.br

3 Doutor e mestre em Teologia. Docente do Programa de Pós-Graduação em Teologia da PUCPR e do Programa de Pós-Graduação em Bioética da PUCPR. Líder do Grupo de Pesquisa Bioética e Humanização do Cuidado em Saúde (BIOHCS) CNPq/PUCPR. Contato: waldir.souza@pucpr.br 
the medical sciences, brings to the everyday scene more and more elderly people with chronic-degenerative diseases. All in their own way will present chronic disease that will last for years and, most likely, when entering the final stage of illness will be patients in Palliative Care. Death will not occur in an unexpected instant, on the contrary, it will be expected and anticipated. The life that stretches presents a new reality: human experiences that did not exist in the past. Thus, a new theological reflection arises provoked by the reality experienced. The question is posed to Theology, since it implies the human being, his spirituality and his search for a sense of living. The humanized and integral care that respects the protagonism of the patient is a concern of Bioethics in helping the practice of medical care. From a brief bibliographic review it was observed that there is confusion between determinant concepts such as religion and spirituality and that there is a need to train spiritual assistants to act in the care of the sick as treatment facilitators.

Keywords: Spiritual Care. Palliative Care. Bioethics. Theology.

\section{Introdução}

Questões prementes da sociedade exigem atenção, especificamente no mundo da saúde, onde há necessidade de ações multiprofissionais que sejam embasadas num conhecimento interdisciplinar. Ciências que se aproximem e se empenhem em agregar as diferentes perspectivas são imprescindíveis para guiar com segurança o estabelecimento de limites de atuação e o aprimoramento do cuidado, tendo como baliza a dignidade da pessoa. A confluência de pontos de vista da Teologia, da Bioética e da Medicina propicia e enseja a interdisciplinaridade. As permutas podem ser conceituais, mas não só. É preciso que se as entenda como práxis, que, por sua vez, pressupõe habilitar para lidar com a complexidade da vida.

A relevância dos aspectos espirituais das pessoas ganha importância ímpar na sociedade plural neste início do século XXI, e está sendo reconhecida pelas ciências médicas. ${ }^{4}{ }^{5}$ Uma vez que dados estatísticos e números são considerados necessários para determinar um conhecimento científico, também as pesquisas quanto aos cuidados em saúde têm se voltado para os aspectos espirituais da pessoa enferma. Um dos subsídios vem da Psicologia, em sua vertente Psicologia da Religião, principalmente pelas expressivas pesquisas quanto ao coping religioso espiritual.,

A Bioética tem trazido contribuições partindo do que lhe é próprio, com uma reflexão ampla e fundamentada, e destaca a humanização das relações no cuidado em

4 CONNELLY, R.; LIGHT, K. Exploring the "new" frontier of spirituality in health care: identifying the dangers. J Relig Health, v. 42, n. 1, p. 35-46, 2003.

5 LUCCHETTI, G. et al. Espiritualidade na prática clínica: o que o clínico deve saber? Spirituality in clinical practice: what should the general practitioner know? Rev Bras Clin Med, v. 8, n. 2, p. 154-158, 2010.

6 FARIA, J. B. de; SEIDEL, E. M. F. Religiosidade e Enfrentamento em Contextos de Saúde e Doença: Revisão da Literatura. Psicologia: Reflexão e Crítica, v. 18, n. 3, p. 381-389, 2005.

7 KOENIG, H. G. Medicina, religião e saúde: o encontro da ciência e da espiritualidade. Porto Alegre: L\&PM, 2012. 
saúde. ${ }^{8}$ Pois, em algum momento, acreditou-se que a tecnologia, expressão objetiva da ciência, resolveria a maior parte dos problemas, logo até resolveria todos. Nisso parece que algo se perdeu em meio às engrenagens, o quê autêntico do humano: as relações. ${ }^{9} 10 \mathrm{O}$ uso dos artefatos, aparelhos, máquinas e chips seria legitimado ao proporcionar mais tempo para as pessoas disporem em atividades não laborais, no entanto parece que acabaram enredadas em mil artimanhas. Elas não se desligam das redes sociais, no entanto, têm dificuldades de estabelecer relações. ${ }^{11}$

E quanto à Teologia? De onde mais poderia vir uma leitura crítica, categórica, valorosa e esperançosa das realidades senão da ciência que apreende seu objeto das manifestações relacionais entre o humano e o seu Sagrado. No universo dos cuidados em final de vida, as pastorais proporcionam algum auxílio espiritual aos enfermos ${ }^{12,13}$ é certo, contudo, é mais um empenho amador, muitas vezes realizado por voluntários e com viés religioso. A empatia parte do sentimento natural de irmandade, de solidariedade, porém é possível potencializar as atitudes e os resultados da ação compassiva. Não se coloca em dúvida o valor da presença dos voluntários e não se prescinde da atuação da capelania hospitalar, entretanto questiona-se o preparo/despreparo para lidar com as demandas. Ao se considerar que saúde também se constitui do bem-estar espiritual, é preciso mudar o foco. Não se trata de partir de saberes intuídos, mas sim de buscar o conhecimento fundamentado. ${ }^{14}$

A preparação daquele que vai prestar o cuidado espiritual à pessoa enferma, à sua família e à equipe médica envolvida pode e deve ser feita com critério. Espera-se que esse profissional tenha ouvidos atentos, um olhar arguto, amplo e ainda assim particular; mãos que levem afago enquanto são firmes para apoiar, um discurso includente, e capacidade de perceber o valor respeitoso do silêncio. Em outras palavras, é necessário saber lidar com o sofrimento, com a dor, com as peculiaridades do ambiente hospitalar, com as limitações advindas da enfermidade; distinguir religiosidade de espiritualidade, compreender a amplitude da sua atuação. ${ }^{15}$ Com isso revelam-se as características do atendimento espiritual: não pode impedir o curso da doença, no entanto, pretende ser libertador, pois pode ajudar a pessoa enferma a dar sentido ao seu sofrimento.

8 PESSINI, L. Bioética: Um Grito por Dignidade de Viver. 4. ed. São Paulo: Paulinas, 2009. 254 p.

9 JONAS, H. O princípio responsabilidade: ensaio de uma ética para a civilização tecnológica. Tradução do original alemão Marijane Lisboa, Luiz Barros Montez. Rio de Janeiro: Contraponto; PUC-Rio, 2006.

${ }^{10}$ CUPUANI, A. Fazer ciência em uma época marcada pela tecnologia. R. Inter. Interdisc. INTERthesis, Florianópolis, v. 11, n. 2, p. 01-14, jul./dez. 2014.

11 LIPOVETSKY, G. A felicidade paradoxal: ensaios sobre a sociedade de hiperconsumo. Tradução Maria Lúcia Machado. São Paulo: Companhia das Letras, 2007.

12 EVANGELISTA, C. B. et al. Palliative care and spirituality: an integrative literature review. Rev Bras Enferm, v. 69, n. 3, p. 554-563, 2016.

${ }^{13}$ FRANCISCO, D. P. et al. Contributions of the chaplaincy service to the care of terminal patients. Texto contexto - enferm., Florianópolis, v. 24, n. 1, p. 212-219, mar. 2015.

14 WORLD HEALTH ORGANIZATION. WHOQOL and spirituality, religiousness and personal beliefs (SRPB). Report on WHO consultation. MNH/MAS/ MHP/98.2 WHO, Genebra, 1998. 22 p.

15 AITKEN, E. V. de P. Assistência Espiritual. In: AYER DE OLIVEIRA, R. (Coord.). Cuidado Paliativo. São Paulo: Conselho Regional de Medicina do Estado de São Paulo, 2008. 689 p. p. 87-90. 
Eis onde a teologia pode prestar serviço ad extra: indo ao encontro pessoal do enfermo, em especial daqueles que estão em Cuidados Paliativos. Não deixa de ser uma oportunidade de trazer do universo dos cuidados em saúde em final de vida conhecimentos empíricos para produzir conhecimento na academia, que, por sua vez, volta a impulsionar a prática pastoral. A missão é formar teólogos que expressem sua vocação profissional trabalhando nos cuidados em final de vida, provisionando-os com conhecimento quanto ao aconselhamento e cuidado pastoral, à liberdade religiosa, ao ecumenismo e diálogo inter-religioso, aos aspectos psicológicos entremeados à religiosidade, e à Tanatologia.

No intuito de humanizar o cuidado em saúde, as equipes de Cuidados Paliativos devem ser multiprofissionais e interdisciplinares para atender a integralidade da pessoa enferma. ${ }^{16}$ A preocupação com a qualidade de vida e de morte do enfermo em fase terminal de doença alcança a prática teológica, que pode contribuir de modo especial, de modo que uma questão se apresenta: é oportuno considerar a presença do teólogo como o assistente espiritual nas equipes de Cuidados Paliativos?

\section{O cenário dos cuidados em saúde que interpela a Teologia}

Os seres humanos contemporâneos são insatisfeitos, hedonistas, iludidos em busca de viver mais e mais, e sempre com juventude, cheios de planos de dominar o universo enquanto ainda passam fome, e constituem uma sociedade histriônica e esquizofrênica. A vida em comunidade mostra sinais de exaustão pela própria dificuldade de encontrar-se, seja devido ao modo capitalista de gerenciar o tempo, seja pelo comportamento individualista crescente. ${ }^{17,18}$

Tudo parece contribuir para sufocar o ritmo natural das coisas: a rapidez e capilarização no mundo da informação, a velocidade com que se dão as constantes mudanças dos artefatos tecnológicos entremeados ao cotidiano das pessoas ${ }^{19}$; a ameaça à autenticidade da vida humana pelas possibilidades técnicas de melhoramento genético; e a relativização dos valores morais e éticos, e a falta do senso de responsabilidade no agir técnico. ${ }^{20}$

Contudo, apesar das inúmeras mudanças, científicas e de comportamento, ainda são necessários nove meses de gestação para a completa formação biológica de um ser humano ${ }^{21}$, e ao final de certo período, bastante variável, a mesma estrutura

${ }^{16}$ CARVAlHO, R. T. de; PARSONS, H. A. (Orgs.). Manual de cuidados paliativos ANCP. Ampliado e atualizado. 2. ed. São Paulo: Academia Nacional de Cuidados Paliativos, 2012.

17 MOSQUERA, J. J. M. Apresentação. In: JOHANN, J. R. Educação e ética: em busca de uma aproximação. Porto Alegre: Edipucrs, 2009. 130 p. p. 7.

18 ARENDT, H. A condição humana. 10. ed. Rio de Janeiro: Forense Universitária, 2007. p. 148-170.

19 MANDEL, A.; SIMON, I.; DELYRA, J. L. Informação: computação e comunicação. Revista USP, n. 35, p. 10-45, nov. 1997. Disponível em: <https://www.revistas.usp.br/revusp/article/view/26865>. Acesso em: 16 out 2017.

20 JONAS, 2006.

${ }^{21}$ PICCININI, C. A. et al. Gestação e a constituição da maternidade. Psicol. estud., Maringá , v. 13, n. 1, p. 63-72, mar. 2008. Disponível em: <http://www.scielo.br/scielo.php?script=sci_arttext\&pid=S1413$-73722008000100008 \& \operatorname{lng}=$ en\&nrm=iso $>$. Acesso em: 22 set. 2017. 
biológica vai à falência. A vida é nascimento e morte, e isso não se altera. No decorrer de sua existência, cada ser humano alcança um status, é embrião, depois feto, recém-nascido, criança, jovem, adulto e velho; é indivíduo, pessoa e sujeito; pode não ser nem pai nem mãe, mas filho sempre será; variam suas características e atributos físicos, intelectuais, relacionais, culturais; nas suas singularidades, é único; tem nome próprio e, por fim, morre. ${ }^{22}$ Responsável ou não, afável ou não, empático ou não, ético ou não, capaz ou não, morre. Tendo fé ou não, sendo religioso ou não, morre.

A interdisciplinaridade entre as ciências médicas, a Bioética e a Teologia se evidencia quando se entrecruzam vida e morte: os cuidados em final de vida. Vê-se que os esforços da Medicina e áreas afins têm alcançado êxito em postergar a morte, graças aos transplantes, à diálise, ao desenvolvimento de novas terapias, técnicas cirúrgicas e medicamentos. ${ }^{23}$ Como resultado desse progresso rápido e muitas vezes irrefletido, o ser humano adquiriu um certo poder: medicalizar a vida. ${ }^{24}$ Inclusive propiciando que as doenças, antes de quadro agudo e curso rápido, possam se estender cronicamente, levando a um prolongamento muitas vezes penoso da existência. ${ }^{25}$

$\mathrm{Na}$ intenção de vencer a batalha e derrotar a morte, muitas vezes as pessoas enfermas são submetidas a tratamentos inúteis e desproporcionados, quando já não há perspectiva de cura, o que acaba configurando uma obstinação terapêutica. Isso é condenável, afinal, tratamentos fúteis ameaçam a dignidade da pessoa. ${ }^{26}$

Como alternativa oferecem-se cuidados chamados de Cuidados Paliativos, especialmente para aqueles enfermos que alcançam a fase terminal da doença como, por exemplo, os atingidos pelas doenças infectocontagiosas humanas terminais (tuberculose resistente, a síndrome da imunodeficiência adquirida), as neoplasias malignas em metástase, e as doenças degenerativas do sistema nervoso em fase final como o mal de Alzheimer. São aqueles cuidados dispensados a fim de dar suporte para o próprio enfermo e para seus familiares, cuidando-se então da vida, nem antecipando a morte (eutanásia $)^{27}$, nem prolongando-a desmedidamente quando já não há possibilidade de cura (distanásia), ${ }^{28}$ permitindo a morte a seu tempo.

A questão é proporcionar a melhor qualidade de vida possível. A avaliação de todos os aspectos da vida do enfermo deve ser levada em conta, uma vez que, além da dor, todo tipo de sofrimento merece atenção. Além de "procurar aliviar a dor e

${ }^{22}$ KOVÁCS, M. J. Bioética nas questões da vida e da morte. Psicol. USP, São Paulo, v. 14, n. 2, p. 115-167, 2003. Disponível em: <http://www.scielo.br/scielo.php?script=sci_arttext\&pid=S0103$-65642003000200008 \& \operatorname{lng}=$ en\&nrm=iso $>$. Acesso em: 22 set. 2017.

${ }^{23}$ KAWAMURA, L. K. Tecnologia e saúde nas diferentes perspectivas de entidades associativas de médicos. Rev. adm. empres., São Paulo, v. 27, n. 2, p. 48-55, jun. 1987.

${ }^{24}$ FOUCAULT, M. Crise da medicina ou crise da antimedicina. Verve. Revista Semestral Autogestionária do Nu-Sol, n. 18, p. 167-194, 2010. Disponível em: <https://revistas.pucsp.br/index.php/verve/article/ view/8646>. Acesso em: 22 set. 2017.

${ }^{25}$ KOVÁCS, 2003.

${ }^{26}$ PESSINI, L. Distanásia: até quando prolongar a vida? São Paulo: Centro Universitário São Camilo; Loyola, 2001.

27 PESSINI, L. Lidando com pedidos de eutanásia: a inserção do filtro paliativo. Rev. Bioética, v. 18, n. 3, p. 549-560, 2010.

${ }^{28}$ PESSINI, 2009. 
outros sintomas angustiantes", a preocupação em "integrar os aspectos psicológicos e espirituais nos cuidados do paciente" tem o intuito de afirmar a vida e encarar o morrer como um processo normal. ${ }^{29}$

O enfrentamento do medo, a depressão, o quadro de dor e sofrimento, as vãs tentativas de barganhar e querer ter o controle da situação culminam num desgaste emocional profundo para o enfermo e sua família. ${ }^{30}$ Nesse momento de final de vida, a biografia da pessoa enferma, sua história de vida, suas crenças, opções e contextos, ganham especial relevância. ${ }^{31}$ Ao mesmo tempo, para cada componente de uma equipe de Cuidados Paliativos, confrontar-se com suas próprias limitações e com a morte do outro deixa próxima a própria morte, não sendo tarefa fácil, requerendo preparo. ${ }^{32}$ É nesse ponto que a assistência espiritual encontra propósito, seja para a pessoa que recebe cuidados em seus últimos e preciosos dias, seja para quem cuida.

Não é descabido perceber que nos cuidados em saúde há um campo de ação para a Teologia, que pode contribuir para que se alcance a justiça, a fraternidade e a solidariedade. Como disse em entrevista o teólogo Rudolf von Sinner ${ }^{33}$, a sociedade interpela a Teologia com suas aflições por motivos "que não têm fronteiras confessionais ou religiosas e atingem a todos", entendendo que temas que envolvem os cuidados em final de vida são desafiantes. As questões bioéticas pedem uma atuação prática, diz Sinner: "É preciso resistir, questionar, mas também amparar, cuidar, compreender, dialogar. Penso que estejamos numa situação nada fácil, mas criativa, onde é preciso encontrar novas respostas e soluções" ${ }^{34}$.

Para onde vai a produção teológica da academia? Como um produto do trabalho do estudo e da pesquisa, por que não levar para atuar junto aos enfermos em final de vida? Cenário de profunda experiência humana, o final de vida em Cuidados Paliativos requisita mais que voluntários bem intencionados e religiosos em atividade pastoral. É ocasião única e derradeira. Portanto é preciso que quem ouve saiba ouvir e tenha o que falar. Requer abertura ao diálogo inter-religioso, e até ao não religioso, e atitudes amadurecidas para prestar serviço qualificado: aquele que pode reconhecer que Deus também pode ali estar se manifestando.

Refletindo sobre a atuação profissional, tome-se, por exemplo, o curso de graduação em Odontologia e suas relativas pós-graduações: forma estudiosos, pes-

29 WORLD HEALTH ORGANIZATION. WHO. OMS. Worldwide Hospice Palliative Care (WHPCA) Alliance. Global atlas of palliative care at the end of life. Genève, 2002. Disponível em: <http://www. who.int/cancer/publications/palliative-care-atlas/en/>. Acesso em: maio 2015.

${ }^{30}$ KÜBLER-ROSS, E. Sobre a morte e o morrer: o que os doentes terminais têm para ensinar a médicos, enfermeiras, religiosos e aos seus próprios parentes. Tradução Paulo Menezes. 7. ed. São Paulo: Martins Fontes, 1997. 299 p.

31 ROSELLÓ, F. T. I. Antropologia do cuidar. Tradução Guilherme Laurito Summa. Petrópolis: Vozes, 2009. 196 p. (Série Enfermagem).

${ }^{32}$ KOVÁCS, M. J. Pensando a morte e a formação de profissionais de saúde. In: CASSORLA, R. M. S. (Coord.). Da morte: estudos brasileiros. Campinas: Papirus; 1991. p. 79-103.

33 SINNER, R. von. Teologia pública. Seus espaços e seu papel. Entrevista. IHUonline, 28 mai. 2008. Disponível em: <http:/www.ihu.unisinos.br/entrevistas/14220-teologia-publica-seus-espacos-e-seu-papel-entrevistaespecial->. Acesso em: mar. 2017.

34 SINNER, 2008. 
quisadores, produtores de conhecimento, também, e principalmente forma profissionais cirurgiões-dentistas. Esses levam o conhecimento à atuação prática e da prática apresentam questões aos estudiosos, numa dinâmica ininterrupta levando à população melhor saúde e bem-estar. Ora, no mesmo raciocínio, se há um curso de graduação em Teologia, que produz estudiosos, pesquisadores e produtores de conhecimento teológico, também forma teólogos que vão executar sua prática no sacerdócio, nas pastorais, na capelania. Eis o ponto da tese proposta: o profissional da capelania hospitalar ${ }^{35}$ pode ser aquele que exerce sua profissão de teólogo, atuando junto aos hospitais e instituições de saúde com o propósito de levar a visão ampla e crítica, para gerenciar as atividades da capelania (voluntariado/agentes de pastoral), assumindo a função direta junto aos Cuidados Paliativos como assistente espiritual, para atender ao paciente, seus familiares e aos membros da equipe. Ou seja, a Teologia se fazendo pública e prática, prestando serviço de qualidade à sociedade, pois em alguns momentos cruciais não basta a boa vontade, é preciso preparo para agir com responsabilidade e ética, solidariedade efetiva, sem emocionalismo nem devocionismo, um exercício de compaixão e fraternidade. ${ }^{36} \mathrm{O}$ desejável é a hospitalidade oferecida com esmero e acolhimento fraterno, expressado num oferecimento ${ }^{37}$, p. ex.: - Te recebo, meu irmão, nesses seus últimos tempos com meu melhor, passemos juntos por mais essa etapa em preparo para o porvir, se tens fé na ressurreição e na vida eterna, se tens fé na reencarnação, se tens fé num nirvana, se tens fé em um Sagrado, se não tens fé e a procura, se não tens fé e quer companhia, aqui estou.

A preocupação com o conforto aos familiares que estão em luto antecipado (e muitas vezes em dúvidas de fé) é própria dos Cuidados Paliativos mesmo após a morte do paciente, pois o cuidado se estende aos familiares. ${ }^{38} \mathrm{Cabem}$ da mesma forma a solidariedade e o apoio aos profissionais que cuidam do paciente, vivenciam sua morte, e no mais das vezes se sentem impotentes e derrotados..$^{39}$ Nesse cenário, portanto, o campo de atuação do assistente espiritual se explicita.

A experiência humana da morte mais que anunciada, prevista com quase exatidão, traz oportunidade única à Teologia, que pode abrir uma porta no "muro eclesial" e estar junto àqueles que por ela passam em Cuidados Paliativos, seja junto ao paciente em final de vida, seja junto ao seu entorno. O teólogo pode trabalhar nos cuidados em saúde auxiliando a interpretar as coisas da vida ordinária em relação às crenças ou até na ausência ou negação dessas, e estará desafiado, como reflete Edward Fowley, pensando a partir de Tracy: "Pergunto-me se um católico romano ou um humanista

${ }^{35}$ MIGUEL, R. P. Psicologia pastoral e bioética em diálogo: o papel do capelão hospitalar na assistência espiritual. In: ESPERANDIO, M. R. G.; KOVÁCS, M. J. (Orgs.). Bioética e psicologia: inter-relações. Curitiba: CRV, 2017. 250 p. p. 113-132.

${ }^{36}$ PLETSCH, R. Diaconia pública: a assistência social da igreja em contexto brasileiro. Estudos Teológicos, v. 43, n. 2, p. 121-125, 2003.

${ }^{37}$ FRANCISCO et al., 2015.

${ }^{38}$ GENEZINI, D. Assistência ao luto. In: CARVALHO; PARSONS (Orgs.), 2012, p. 569-582.

39 PITTA, A. Hospital: dor e morte como ofício. 4. ed. São Paulo: Hucitec, 1999. 
em um hospital podem, de fato, compartilhar algum tipo de reflexão profunda a respeito do trabalho que realizam juntos sem comprometer as suas formas de crença?"40.

Contudo, é possível um diálogo até mesmo com não teístas a partir da percepção cristológica de Tracy. No mesmo sentido, é possível recordar que Jesus também esteve consolado (pela presença de Maria e João) ${ }^{41}$ e consolando nos seus últimos momentos, sabia que a morte era certa e iminente, e consolava quem cria e quem não cria (os crucificados ao seu lado).

\section{A interdisciplinaridade na assistência espiritual ao enfermo}

Em virtude da possibilidade de prolongar a vida inclusive nos momentos finais, novas atitudes têm sido necessárias: o indivíduo passou a ter que refletir sobre o direito de morrer de modo natural, sem excessos terapêuticos inúteis e desproporcionais. Os Cuidados Paliativos passaram a ser uma opção legítima e adequada, proporcionando tempo e ocasião propícia para receber cuidado espiritual. ${ }^{42,43}$

A complexidade do trabalho que envolve as equipes paliativistas, de formação multiprofissional, é reconhecida. ${ }^{44,45}$ Reis $^{46}$ traz que se recomenda minimamente: "Para início das atividades de um Serviço de Cuidado Paliativo sugere-se a presença dos seguintes profissionais: médico, enfermeiro, técnico de enfermagem, psicólogo, assistente social e capelão (orientador espiritual) [...]". Devolver a autonomia ao paciente é primordial para o estabelecimento de um Cuidado Paliativo de excelência, que considere a qualidade de vida e com isso a integralidade do ser, sendo fácil compreender que esse é um trabalho interdisciplinar.

A importância e relevância da religiosidade/espiritualidade mostram-se indiscutíveis. É comum a muitos autores que a relação espiritualidade-saúde merece aten-

${ }^{40}$ FOWLEY, E. A Imaginação Analógica: a teologia cristã e a cultura do pluralismo. Entrevista. IHUonline, 18 março 2016. Disponível em: <http://www.ihu.unisinos.br/552743-a-imaginacao-analogica-a-teologia-crista-e-a-cultura-do-pluralismo>. Acesso em: mar. 2017.

${ }^{41}$ BÍBLIA de Jerusalém. João 19. 25-27. 9. reimpressão. São Paulo: Paulus, 2013.

42 FRANCISCO et al., 2015.

${ }^{43}$ MIGUEL, 2017.

${ }^{44}$ KAPPAUN, N. R. C. Assistência em cuidados paliativos: o trabalho em saúde no lidar com o processo de morrer. 2013. 71 f. Dissertação (Mestrado) - Escola Nacional de Saúde Pública Sergio Arouca, Rio de Janeiro, 2013.

45 SILVA, A. P. et al. Cuidados Paliativos como Prática Humanizadora em um Hospital Público (p. 281). In: Anais do Congresso Internacional de Humanidades \& Humanização em Saúde (Blucher Medical Proceedings, v. 1, n. 2). São Paulo: Blucher, 2014. p. 281.

46 REIS, B. F. S. Projeto I Simpósio de Cuidado Paliativo da Zona da Mata Mineira. II Simpósio de Cuidados Paliativos de Juiz de Fora. I Simpósio de Cuidado Paliativo Oncológico da ASCOMCER. Juiz de Fora, 03 de março de 2015. 
ção e pesquisa, sendo o aconselhamento espiritual um parceiro no cuidado integral em saúde, na busca de formas de enfrentamento. ${ }^{47,48,49}$

No estudo feito por Francisco et al..$^{50}$, a espiritualidade é considerada relevante e é explorada como preocupação e contribuição do serviço de capelania ao cuidado de pacientes em fase terminal de doença. Esses autores destacam o impacto que as crenças e as práticas espirituais/religiosas representam no auxílio ao enfrentamento do desequilíbrio na saúde das pessoas, no preparo para a morte e até nas relações interpessoais dos profissionais da saúde.

A presença do capelão é considerada como condição importantíssima no atendimento dos Cuidados Paliativos, por Vasconcelos ${ }^{51}$ e $\mathrm{Cassol}^{52}$, os autores trazem o capelão ou conselheiro espiritual como participante das equipes, mas sem comentários específicos de sua ação. No entanto, detêm-se quanto à ação do capelão como mediador entre pacientes, familiares e equipe de saúde. Também relatam sobre essa mediação Melo, Valero e Menezes.$^{53}$ Enquanto outros referem-se à capelania como importante, mas não como parte integrante das equipes multiprofissionais, apenas citam os capelães.$^{54,55,56} \mathrm{~A}$ respeito da preocupação com as diferenças de credo, Giumbelli ${ }^{57}$ defende a formação de fórum inter-religioso em hospitais porque acredita que "existência de capelanias coloca sempre alguma forma de limitação a priori da diversidade". Enquanto, para Hoepfner ${ }^{58}$, a assistência espiritual é defendida e proposta como uma "práxis específica de cuidado", como competência e desafio para a teologia, numa perspectiva ecumênica que venha a contribuir para a humanização do cuidado hospitalar.

${ }^{47}$ ARRIEIRA, I. C. O. et al. Espiritualidade na equipe interdisciplinar que atua em cuidados paliativos às pessoas com câncer. Ciência, Cuidado e Saúde, v. 10, n. 2, 2012.

${ }^{48}$ RODRIQUES, R. R. O aconselhamento pastoral e a sua abordagem em pacientes oncológicos: da crise à intervenção. 2012. 94 f. Dissertação (Mestrado) - Programa de Pós-Graduação em Teologia da Faculdades EST, São Leopoldo, 2012.

${ }^{49}$ GOBATTO, C. A.; ARAÚJO, T. C. C. F. Religiosidade e espiritualidade em oncologia: concepções de profissionais da saúde. Psicologia-USP, São Paulo, v. 24, n. 1, p. 11-34, abr. 2013.

${ }^{50}$ FRANCISCO et al., 2015.

51 VASCONCELOS, M. F. et al. Purposes of palliative care for the patient with hiv/aids: A study with nurses. Revista de Pesquisa Cuidado é Fundamental, v. 6, n. 3, p. 1.058-1.067, jul. 2014.

52 CASSOL, P. B. Autonomia do paciente terminal: percepção da enfermagem de uma unidade de internação hemato oncológica. 2014. 85f. Dissertação (Mestrado) - Centro de Ciências da Saúde, Programa de Pós-Graduação em Enfermagem, Universidade Federal de Santa Maria, Santa Maria/RS, 2014.

${ }^{53}$ MELO, A. C.; VALERO, F. F.; MENEZES, M. A intervenção psicológica em cuidados paliativos. Psicologia, Saúde \& Doenças, Lisboa, v. 14, n. 3, nov. 2013.

${ }^{54}$ SCHIMIDT, T. C. G.; NASCIMENTO V. S. R. O cotidiano do trabalho em cuidados paliativos na percepção dos profissionais de saúde. Enfermagem Brasil, v. 11, n. 5, p. 294-300, set. /out. 2012.

${ }^{55}$ KAPPAUN, 2013.

${ }^{56}$ SILVA et al., 2014.

${ }^{57}$ GIUMBELLI, E. A religião em hospitais: espaços (inter) religiosos em Porto Alegre [ou O(s) lugar(es) $\mathrm{da}(\mathrm{s})$ religião(ões) em um hospital]. Projeto (CNPq) Presença religiosa no espaço público no Brasil em três âmbitos. Anais. 28 Reunião Brasileira de Antropologia, julho de 2012, São Paulo, SP, Brasil. p. 25.

${ }^{58}$ HOEPFNER, D. A. Cuidado pastoral num centro de tratamento intensivo adulto: referências bíblico-teológicas e competências pastorais. 2012. Tese (Doutorado) - Programa de Pós-Graduação em Teologia da Faculdades EST, São Leopoldo, 2012. 
A assistência espiritual apropriadamente conduzida e instrumentalizada pode fluir e refluir, pois dela fazem jus os enfermos e os cuidadores. ${ }^{59,60,61}$ Há dificuldade dos profissionais que se ocupam dos cuidados em saúde de se apropriarem e agregarem conceitos de espiritualidade, mesmo que reconheçam a importância de sua relação com a saúde. ${ }^{62,63} \mathrm{O}$ sofrimento dos profissionais que atuam junto aos enfermos em final de vida foi relatado por Schimidt e Nascimento ${ }^{64}$, assim como por Rutz Porto e colaboradores. ${ }^{65}$ Nessas pesquisas, os profissionais afirmaram sentir necessidade de buscar formação complementar no que se refere à terminalidade. Inclusive a morte continua sendo algo a ser derrotado, o que acaba por significar fracasso ao médico. ${ }^{66}$

Religiosidade e espiritualidade se confundem e se mostram ferramentas usadas como busca de proteção e cura em pacientes oncológicos, conforme estudos de Arrieira et al. ${ }^{67}$, Kappaun ${ }^{68}$ e de Francisco et al. ${ }^{69}$ Já no estudo de Oliveira sobre a religiosidade do idoso em tratamento oncológico, a resiliência é tida como consequência da vivência de religiosidade e fruto de fé na cura. ${ }^{70}$

Conquanto ainda esteja presente certa confusão entre religião e espiritualidade, Oliveira $^{71}$ e Silva ${ }^{72}$ trazem ressalvas destacando que uma não está necessariamente vinculada à outra. Essa mistura de conceitos parece ecoar na Constituição Brasileira de 1988, que no seu Art. 5 , $V_{\text {VII }}^{73}$ assegura "a prestação de assistência religiosa nas entidades civis e militares de internação coletiva”. E a Lei n. 9.982 de $2000^{74}$ regulamenta a

59 GOBATTO; ARAÚJO, 2013.

${ }^{60}$ DOMINGUES, G. R. et al. A atuação do psicólogo no tratamento de pacientes terminais e seus familiares. Psicologia hospitalar, São Paulo, v. 11, n. 1, jan. 2013.

${ }^{61}$ KAPPAUN, N. R. C.; GOMEZ, C. M. O trabalho de cuidar de pacientes terminais com câncer. Ciênc. saúde coletiva, v.18, n. 9, p. 2.549-2.557, 2013.

${ }^{62}$ COSTA, I. C. P. Cuidados paliativos na atenção básica: depoimentos de profissionais da saúde. 2012. 120 f. Dissertação (Mestrado) - CCS, UFPB, João Pessoa, 2012

${ }^{63}$ ESPERANDIO, M. R. G. Teologia e a pesquisa sobre espiritualidade e saúde: um estudo piloto entre profissionais da saúde e pastoralistas. Horizonte - Dossiê: Espiritualidades não-religiosas. Belo Horizonte, v. 12 , n. 35 , p. 805-832, jul./set. 2014.

${ }^{64}$ SCHIMIDT; NASCIMENTO, 2012.

${ }^{65}$ RUTZ PORTO, A. et al. Visão dos profissionais sobre seu trabalho no programa de internação domiciliar interdisciplinar oncológico: uma realidade brasileira. Avances en Enfermería, Bogotá, v. 32, n. 1, jan. 2014.

${ }^{66}$ PEREIRA, H. A. A Integração dos Cuidados Paliativos nas Unidades de Terapia Intensiva de Adultos: uma reflexão Bioética. 2012. 132 f. Dissertação (Mestrado) - Faculdade de Medicina, Universidade Federal Fluminense, Niterói, 2012.

${ }^{67}$ ARRIEIRA et al., 2012.

${ }^{68}$ KAPPAUN, 2013.

${ }^{69}$ FRANCISCO et al., 2015.

${ }^{70}$ OLIVEIRA, I. R. A religiosidade e o idoso: fator de proteção no tratamento de câncer. 2012. 138 f. Dissertação (Mestrado) - Universidade Católica de Brasília, 2012.

71 OLIVEIRA, 2012.

${ }^{72}$ SILVA, M. A. A espiritualidade na atenção em saúde em geral no Brasil. 2013. 37 f. Monografia (Bacharelado em Terapia Ocupacional) - Universidade de Brasília, Brasília, 2013.

${ }^{73}$ BRASIL. Constituição da República Federativa do Brasil. Brasília: Senado Federal: Centro Gráfico, 1988. 292 p.

${ }^{74}$ BRASIL. Lei n. 9.982, de 14 de julho de 2000. Dispõe sobre a prestação de assistência religiosa nas entidades hospitalares públicas e privadas, bem como nos estabelecimentos prisionais civis e militares. 
prestação de assistência religiosa, propondo que os religiosos tenham acesso aos hospitais, no entanto é preciso atenção ao fato de que a assistência religiosa e a espiritual não são sinônimos. É necessário que se diferenciem, enfatizam Silva ${ }^{75}$ e Domingues et al. ${ }^{76}$, para prestar melhor atenção e cuidado ao enfermo, uma vez que as religiões tratam de formatar a espiritualidade, enquanto que esta independe da religião.

Cervelin $^{77}$ reconhece que os profissionais da saúde e pacientes são fortemente influenciados pelos discursos religiosos e espirituais, e aponta o quanto procuram normatizar o comportamento frente à morte. O autor traz que a assistência espiritual nem sempre é qualificada e, para exemplificar, cita Taylor, que define como função da enfermagem fazer avaliação espiritual. Outra afirmação que demonstra aparentemente um equívoco de funções é a que relata como o terapeuta ocupacional mediador entre família e capelão. ${ }^{78}$

Curiosamente, Marinho et al. ${ }^{79}$ discorrem sobre a formação e implementação de comitês de bioética hospitalar, incluindo aí teólogos, o que até denota uma busca de assistência espiritual, mas não fazem menção à presença nas equipes que atuam junto ao enfermo. Enquanto que o cuidado espiritual como afazer da capelania aparece inclusive como uma prescrição: "Um atendimento espiritual diário e individual a todos, oportunidades de reflexão sobre as questões existenciais, perdão, vida eterna, qualidade e utilidade de vida" $"$.

Quanto à demanda acerca da formação para o enfrentamento das questões que envolvam aspectos referentes à dimensão espiritual, é pertinente considerar que "a teologia pode contribuir na reflexão teórica sobre espiritualidade e saúde, e na colaboração com outras ciências na formação destes profissionais acerca do tema", diz Esperandio. ${ }^{81}$

A capacitação dos profissionais parece ser ponto de convergência ${ }^{82,83,84}$ para dar um cunho formal, porque exige capacidade de acolher e deliberar, a partir dos valores da pessoa enferma, portanto assistência espiritual não se trata só de boa vontade e fé, havendo necessidade de formação e treinamento.

Diário Oficial da União. Seção 1. 17/7/2000, p. 3. (Publicação Original). Disponível em: <http://www. planalto.gov.br/ccivil_03/Leis/L9982.htm>. Acesso em: dez. 2016.

75 SILVA, 2013.

${ }^{76}$ DOMINGUES et al., 2013

${ }^{77}$ CERVELIN, A. F. Cuidados paliativos: uma análise dos discursos sobre espiritualidade e religiosidade. Trabalho de Conclusão de Curso. Escola de Enfermagem, UFRGS, 2012.

78 GARCIA-SCHINZARI, N. R.; SPOSITO, A. M. P.; PFEIFER, L. I. Cuidados paliativos junto a crianças e adolescentes hospitalizados com câncer: o papel da terapia ocupacional. Revista Brasileira de Cancerologia, v. 59, n. 2, p. 239-247, 2013.

79 MARINHO, S. et al. Implementación de comités de bioética en hospitales universitarios brasileños: dificultades y viabilidades. Revista Bioética, Brasília. v. 22, n. 1, p. 105-115, abr. 2014.

${ }^{80}$ AITKEN, E. V. P. Entre a vida e a morte, 2006 apud DOMINGUES et al., 2013, p. 8.

${ }^{81}$ ESPERANDIO, 2014, p. 805.

${ }^{82}$ SILVA, 2013

${ }^{83}$ GOBATTO et al., 2013.

${ }^{84}$ ESPERANDIO, 2014. 
Pode-se inferir do exposto que há necessidade da assistência espiritual nos cuidados em saúde e que a formação dos capelães e voluntários parece ser insuficiente. É possível o avanço da ciência teológica para o espaço público, especificamente aquele ligado à prestação de cuidados em saúde, tendo a atuação do teólogo como o profissional responsável pela assistência espiritual em ambientes hospitalares. Urge ampliar as posturas para além da religião e valorizar a espiritualidade de cada um, nem sempre reconhecida pelos símbolos e ritos, contudo, certamente presente em cada ser humano. Kovács ${ }^{85}$, sobre a necessidade do suporte espiritual, escreve que "há limite para tratamentos e não para cuidados nas várias dimensões do sofrimento humano". O intuito movente é oferecer alento significante e significativo para aqueles que estão mais próximos do final da vida e enfermos.

\section{Considerações finais}

A proposta do texto de buscar meios que contribuam para humanizar as relações de cuidado num diálogo direto e necessário incluindo Teologia, Medicina e Bioética foi alcançada. O protagonismo do paciente, o respeito à dignidade da pessoa humana e as subjetividades de todos os envolvidos são demandas interdisciplinares que podem ser atendidas na oferta dos Cuidados Paliativos onde a assistência espiritual seja oferecida por um profissional com formação em Teologia e preparado para a capelania hospitalar.

No que corresponde ao sofrimento e dor, é preciso avançar, não se tratando de encontrar uma finalidade. Há, sim, possibilidade de dar sentido ao sofrimento que mesmo sendo inescapável pode ganhar contornos positivos. Valorizar as experiências pelas quais o ser humano passa nos seus últimos meses e dias e delas apreender um sentido para a vida é um fazer teológico. O controle da dor é primordial nos cuidados em final de vida, nesse sentido a Teologia pode cuidar da dor existencial enquanto os cuidados médicos evitam o padecimento doloroso.

Uma vez que a humanização do cuidado em saúde é expressão máxima de uma postura ética para com a dignidade da vida, pode e deve contemplar a espiritualidade do enfermo, sendo relevante a participação profissional de um assistente espiritual nas equipes interdisciplinares, nos setores ou equipes de Cuidados Paliativos dos hospitais, institutos de longa permanência e demais estabelecimentos de saúde.

\section{Referências}

AITKEN, E. V. de P. Assistência Espiritual. In: AYER DE OLIVEIRA, R. (Coord.). Cuidado Paliativo. São Paulo: Conselho Regional de Medicina do Estado de São Paulo, 2008. 689 p. p. 87-90. ARENDT, H. A condição humana. 10. ed. Rio de Janeiro: Forense Universitária, 2007. p. 148-170. ARRIEIRA, I. C. O. et al. Espiritualidade na equipe interdisciplinar que atua em cuidados paliativos às pessoas com câncer. Ciência, Cuidado e Saúde, v. 10, n. 2, 2012.

${ }^{85}$ KOVÁCS, M. J. Towards death with dignity in the XXI Century. Revista Bioética, Brasília, v. 22, n. 1, p. $94-104$, jan./abr. 2014. p. 101. 
BÍBLIA de Jerusalém. 9. reimpressão. São Paulo: Paulus, 2013.

BRASIL. Constituição da República Federativa do Brasil. Brasília: Senado Federal: Centro Gráfico, 1988. 292 p.

BRASIL. Lei n. 9.982, de 14 de julho de 2000. Dispõe sobre a prestação de assistência religiosa nas entidades hospitalares públicas e privadas, bem como nos estabelecimentos prisionais civis e militares. Diário Oficial da União. Seção 1. 17/7/2000, p. 3 (Publicação Original). Disponível em: <http://www.planalto.gov.br/ccivil_03/Leis/L9982.htm>. Acesso em: dez. 2016.

CARVALHO, R. T. de; PARSONS, H. A. (Orgs.). Manual de cuidados paliativos ANCP. Ampliado e atualizado. 2. ed. São Paulo: Academia Nacional de Cuidados Paliativos, 2012.

CASSOL, P. B. Autonomia do paciente terminal: percepção da enfermagem de uma unidade de internação hemato oncológica. 2014. 85 f. Dissertação (Mestrado) - Centro de Ciências da Saúde, Programa de Pós-Graduação em Enfermagem, Universidade Federal de Santa Maria, Santa Maria/RS, 2014.

CERVELIN, A. F. Cuidados paliativos: uma análise dos discursos sobre espiritualidade e religiosidade. Trabalho de Conclusão de Curso (Escola de Enfermagem) - UFRGS, 2012.

CONNELLY, R.; LIGHT, K. Exploring the "new" frontier of spirituality in health care: identifying the dangers. J Relig Health, v. 42, n. 1, p. 35-46, 2003.

COSTA, I. C. P. Cuidado paliativos na atenção básica: depoimentos de profissionais da saúde. 2012. 120 f. Dissertação (Mestrado) - CCS, UFPB, João Pessoa, 2012.

CUPUANI, A. Fazer ciência em uma época marcada pela tecnologia. R. Inter. Interdisc. INTERthesis, Florianópolis, v. 11, n. 2, p. 01-14, jul./dez. 2014.

DOMINGUES, G. R. et al. A atuação do psicólogo no tratamento de pacientes terminais e seus familiares. Psicologia hospitalar, São Paulo, v. 11, n. 1, p. 2-24, jan. 2013. Disponível em: $<$ http://pepsic.bvsalud.org/scielo.php?script=sci_arttext\&pid=S167774092013000100002\&ln $\mathrm{g}=\mathrm{pt \& nrm}=\mathrm{iso}>$. Acesso em: jul. 2015.

ESPERANDIO, M. R. G. Teologia e a pesquisa sobre espiritualidade e saúde: um estudo piloto entre profissionais da saúde e pastoralistas. Horizonte - Dossiê: Espiritualidades não-religiosas. Belo Horizonte, v. 12, n. 35, p. 805-832, jul./set. 2014.

EVANGELISTA, C. B. et al. Palliative care and spirituality: an integrative literature review. Rev Bras Enferm, v. 69, n. 3, p. 554-63, 2016. DOI: http://dx.doi.org/10.1590/0034-7167.2016690324i. FARIA, J. B. de; SEIDEL, E. M. F. Religiosidade e Enfrentamento em Contextos de Saúde e Doença: Revisão da Literatura. Psicologia: Reflexão e Crítica, v. 18, n. 3, p. 381-389, 2005.

FRANCISCO, D. P. et al. Contributions of the chaplaincy service to the care of terminal patients. Texto \& contexto enferm, v. 24, n. 1, p. 212-219, jan./mar. 2015. DOI: 10.1590/010407072015003180013.

FOUCAULT, M. Crise da medicina ou crise da antimedicina. Verve. Revista Semestral Autogestionária do Nu-Sol, n. 18, p. 167-194, 2010. Disponível em: <https://revistas.pucsp.br/index. php/verve/article/view/8646>. Acesso em: 22 set. 2017.

FOWLEY, E. A Imaginação Analógica: a teologia cristã e a cultura do pluralismo. Entrevista. IHUonline 18 março 2016. Disponível em: <http://www.ihu.unisinos.br/552743-a-imaginacao-analogica-a-teologia-crista-e-a-cultura-do-pluralismo>. Acesso em: set. 2016.

GARCIA-SCHINZARI, N. R.; SPOSITO, A. M. P.; PFEIFER, L. I. Cuidados paliativos junto a crianças e adolescentes hospitalizados com câncer: o papel da terapia ocupacional. Revista Brasileira de Cancerologia, v. 59, n. 2, p. 239-247, 2013.

GENEZINI, D. Assistência ao luto. In: CARVALHO, R. T. de; PARSONS, H. A. (Orgs.). Manual de cuidados paliativos ANCP. Ampliado e atualizado. 2. ed. São Paulo: Academia Nacional de Cuidados Paliativos, 2012. p. 569-582. 
GIUMBELLI, E. A religião em hospitais: espaços (inter) religiosos em Porto Alegre [ou O (s) lugar (es) da (s) religião (ões) em um hospital]. Projeto (CNPq) "Presença religiosa no espaço público no Brasil em três âmbitos". Anais. 28ª Reunião Brasileira de Antropologia, julho de 2012. São Paulo, SP, Brasil. Disponível em: <http://www.abant.org.br/conteudo/ANAIS/ CD_Virtual_28_RBA/programacao/grupos_trabalho/artigos/gt58/Emerson\%20Giumbelli.pdf $>$. Acesso em: jul. 2015.

GOBATTO, C. A.; ARAÚJO, T. C. C. F. Religiosidade e espiritualidade em oncologia: concepções de profissionais da saúde. Psicologia-USP, São Paulo, v. 24, n. 1, p. 11-34, abr. 2013.

HOEPFNER, D. A. Cuidado pastoral num centro de tratamento intensivo adulto: referências bíblico-teológicas e competências pastorais. 2012. Tese (Doutorado) - Programa de Pós-Graduação em Teologia da Faculdades EST, São Leopoldo, 2012.

JONAS, H. O princípio responsabilidade: ensaio de uma ética para a civilização tecnológica. Tradução do original alemão Marijane Lisboa, Luiz Barros Montez. Rio de Janeiro: contraponto: PUC- Rio, 2006.

KAPPAUN, N. R. C. Assistência em cuidados paliativos: o trabalho em saúde no lidar com o processo de morrer. 2013. 71 f. Dissertação (Mestrado) - Escola Nacional de Saúde Pública Sergio Arouca, Rio de Janeiro, 2013.

KAPPAUN, N. R. C.; GOMEZ, C. M. O trabalho de cuidar de pacientes terminais com câncer. Ciênc. saúde coletiva, v. 18, n. 9, p. 2.549-2.557, 2013.

KAWAMURA, L. K. Tecnologia e saúde nas diferentes perspectivas de entidades associativas de médicos. Rev. adm. empres., São Paulo, v. 27, n. 2, p. 48-55, jun. 1987. DOI.10.1590/S003475901987000200007.

KOENIG, H. G. Medicina, religião e saúde: o encontro da ciência e da espiritualidade. Porto Alegre: L\&PM, 2012.

KOVÁCS, M. J. Pensando a morte e a formação de profissionais de saúde. In: CASSORLA, R. M. S. (Coord.). Da morte: estudos brasileiros. Campinas: Papirus; 1991. p. 79-103.

Bioética nas questões da vida e da morte. Psicol. USP, São Paulo, v. 14, n. 2, p. 115-

167, 2003. Disponível em: <http://www.scielo.br/scielo.php?script=sci_arttext\&pid=S0103-6>. Acesso em: set. 2017.

. Towards death with dignity in the XXI Century. Revista Bioética, Brasília, v. 22, n. 1, p. 94-104, jan./abr. 2014.

KÜBLER-ROSS, E. Sobre a morte e o morrer: o que os doentes terminais têm para ensinar a médicos, enfermeiras, religiosos e aos seus próprios parentes. Tradução Paulo Menezes. 7. ed. São Paulo: Martins Fontes, 1997. 299 p.

LIPOVETSKY, G. A felicidade paradoxal: ensaios sobre a sociedade de hiperconsumo. Tradução Maria Lúcia Machado. São Paulo: Companhia das Letras, 2007.

LUCCHETTI, G. et al. Espiritualidade na prática clínica: o que o clínico deve saber? Spirituality in clinical practice: what should the general practitioner know? Rev Bras Clin Med, v. 8, n. 2, p. 154-158, 2010.

MANDEL, A.; SIMON, I.; DELYRA, J. L. Informação: computação e comunicação. Revista USP, n. 35, p. 10-45, nov. 1997. Disponível em: <https://www.revistas.usp.br/revusp/article/ view/26865>. Acesso em: 16 out 2017.

MARINHO, S. et al. Implementación de comités de bioética en hospitales universitarios brasileños: dificultades y viabilidades. Revista Bioética, Brasília, v. 22, n. 1, p. 105-115, abr. 2014. MELO, A. C.; VALERO, F. F.; MENEZES, M. A intervenção psicológica em cuidados paliativos. Psicologia, Saúde \& Doenças, Lisboa, v. 14, n. 3, nov. 2013. 
MIGUEL, R. P. Psicologia pastoral e bioética em diálogo: o papel do capelão hospitalar na assistência espiritual. In: ESPERANDIO, M. R. G.; KOVÁCS, M. J. (Orgs.). Bioética e psicologia: inter-relações. Curitiba: CRV, 2017. 250 p. p. 113-132.

MOSQUERA, J. J. M. Apresentação. In: JOHANN, J. R. Educação e ética: em busca de uma aproximação. Porto Alegre: Edipucrs, 2009. 130 p. p. 7.

OLIVEIRA, I. R. A religiosidade e o idoso: fator de proteção no tratamento de câncer. 2012. 138 f. Dissertação (Mestrado) - Universidade Católica de Brasília, 2012.

PEREIRA, H. A. A Integração dos Cuidados Paliativos nas Unidades de Terapia Intensiva de Adultos: uma reflexão Bioética. 2012. 132 f. Dissertação (Mestrado) - Faculdade de Medicina, Universidade Federal Fluminense, Niterói, 2012.

PESSINI, L. Distanásia: até quando prolongar a vida? São Paulo: Centro Universitário São Camilo; Loyola, 2001.

Bioética: um grito por dignidade de viver. 4. ed. São Paulo: Paulinas, 2009. 254 p.

Lidando com pedidos de eutanásia: a inserção do filtro paliativo. Rev. Bioética, v. 18, n. 3, p. 549-560, 2010.

PICCININI, C. A. et al. Gestação e a constituição da maternidade. Psicol. estud., Maringá, v. 13, n. 1, p. 63-72, mar. 2008. Disponível em: $<$ http://www.scielo.br/scielo.php?script=sci_arttext\& pid $=$ S141373722008000100008\&lng=en\&nrm=iso $>$. Acesso em: 22 set. 2017

PITTA, A. Hospital: dor e morte como ofício. 4. ed. São Paulo: Hucitec, 1999.

PLETSCH, R. Diaconia pública: a assistência social da igreja em contexto brasileiro. Estudos Teológicos, v. 43, n. 2, p. 121-125, 2003.

REIS, B. F. S. Projeto I Simpósio de Cuidado Paliativo da Zona da Mata Mineira. II Simpósio de Cuidados Paliativos de Juiz de Fora. I Simpósio de Cuidado Paliativo Oncológico da ASCOMCER. Juiz de Fora, 03 de março de 2015.

RODRIQUES, R. R. O aconselhamento pastoral e a sua abordagem em pacientes oncológicos: da crise à intervenção. 2012. 94 f. Dissertação (Mestrado) - Programa de Pós-Graduação em Teologia da Faculdades EST, São Leopoldo, 2012.

ROSELLÓ F. T. i. Antropologia do cuidar. Tradução Guilherme Laurito Summa. Petrópolis: Vozes, 2009. 196 p. (Série Enfermagem).

RUTZ PORTO, A. et al. Visão dos profissionais sobre seu trabalho no programa de internação domiciliar interdisciplinar oncológico: uma realidade brasileira. Avances en Enfermería, Bogotá, v. 32, n. 1, jan. 2014.

SCHIMIDT, T. C. G.; NASCIMENTO V. S. R. O cotidiano do trabalho em cuidados paliativos na percepção dos profissionais de saúde. Enfermagem Brasil, v. 11, n. 5, p. 294-300, set./out. 2012. SILVA, M. A. A espiritualidade na atenção em saúde em geral no Brasil. 2013. 37 f. Monografia (Bacharelado em Terapia Ocupacional) - Universidade de Brasília, Brasília, 2013.

SILVA, A. P. et al. Cuidados Paliativos como Prática Humanizadora em um Hospital Público. In: Anais do Congresso Internacional de Humanidades \& Humanização em Saúde (Blucher Medical Proceedings, v. 1, n. 2). São Paulo: Blucher, 2014. p. 281.

SINNER, R. von. Teologia pública. Seus espaços e seu papel. Entrevista. IHUonline, 28 mai. 2008. Disponível em: <http://www.ihu.unisinos.br/entrevistas/14220-teologia-publica-seus espacos-e-seu-papel-entrevistaespecial->. Acesso em: mar. 2017.

VASCONCELOS, M. F. et al. Purposes of palliative care for the patient with hiv/aids: A study with nurses. Revista de Pesquisa Cuidado é Fundamental, v. 6, n. 3, p. 1.058-1.067, jul. 2014. WORLD HEALTH ORGANIZATION. WHOQOL and spirituality, religiousness and personal beliefs (SRPB). Report on WHO consultation. MNH/MAS/ MHP/98.2 WHO, Genebra, 1998. 22 p. WORLD HEALTH ORGANIZATION. WHO. OMS. Worldwide Hospice Palliative Care (WHPCA) Alliance. Global atlas of palliative care at the end of life. Genève, 2002. Disponível em: < http://www.who.int/cancer/publications/palliative-care-atlas/en/>. Acesso em: mai. 2015. 